\title{
UM OLHAR SOBRE O ENSINO DE HISTÓRIA NOS MUSEUS DE CIÊNCIA
}

\author{
Déborah Roberta Santiago Chaves Vilela \\ Zenaide Gregório Alves ${ }^{2}$ \\ Rozeane Porto Diniz ${ }^{3}$
}

\begin{abstract}
Resumo: A partir das variadas definições de museus e de seus potenciais educativos, pretendemos analisar nesse estudo, em consonância com a Declaração do Rio de Janeiro de 1958 e outros decretos/leis, tais como a Lei 11.904/2009 e as Diretrizes Curriculares Nacionais - Base nacional Comum Curricular e a Matriz do Exame Nacional do Ensino Médio, pensando como os museus de ciência enquanto divulgadores da cultura científica, as suas relações entre ciência, tecnologia, sociedade e História, podem ser explorados dentre as suas possibilidades de integração com o Ensino de História.
\end{abstract}

Palavras-chave: Ensino de História. Museus. Museus de ciência. Educação.

\section{A LOOK AT THE TEACHING OF HISTORY IN SCIENCE MUSEUMS}

Abstract: Based on the varied definitions of museums and their educational potentials, we intend to analyze this study, in line with the Rio de Janeiro Declaration of 1958 and other decrees / laws, such as Law 11.904 / 2009 and the National Curriculum Guidelines - National basis Common Curriculum and the National High School Examination Matrix, thinking how science museums as disseminators of scientific culture, their relations between science, technology, society and history, can be explored among their possibilities of integration with History Teaching.

Keywords: History teaching. Museums. Science museums. Education.

\footnotetext{
${ }^{1}$ Mestre em História pelo Programa de Pós-graduação em História Social e da Cultura Regional da UFRPE. Especialista em Ensino de História do Brasil pela FAINTVISA. Graduada em Licenciatura em História pela UFRPE. Dedicada às pesquisas na área de História e Museus, tem desenvolvido trabalhos voltados para questões do Ensino de História e Educação em Museus. Pesquisadora e membro do Laboratório de Estudos e Intervenção em Patrimônio cultural e Memória social (LEPAM). Professora na Educação Básica (Anos Finais) e Superior - Professora colaboradora da Faculdade do Sertão do Pajeú FASP.

${ }^{2}$ Mestre Stricto Sensu em História pelo Programa de Pós-graduação em História Social e da Cultura Regional - PGH - Universidade Federal Rural de Pernambuco. É pesquisadora e membro do Laboratório de Estudos e Intervenção em Patrimônio cultural e Memória social (LEPAM), atuando com ênfase em Ensino de História. Já atuou em turmas da graduação em História, por meio do Estágio de Docência. É Graduada em Licenciatura Plena em História pela UFRPE e Pós-graduada Lato Sensu em Educação pela FAFIRE. Atualmente está vinculada à Secretaria de Turismo do Estado de Pernambuco, como servidora pública temporária.

3 Pós-Doutoranda em História pela UFRPE. Doutora em Literatura e Interculturalidade pela UEPB. Mestra em História pela UFPB e em Literatura e Interculturalidade pela UEPB. Graduada em História pela UEPB. Graduada em Letras Língua Portuguesa pela UFPB. Dedicada à pesquisas na área de História e Literatura, tem desenvolvido trabalhos com discussões voltadas para a história das mulheres e dos negros em Olivedos-PB (Farol de Joana Preta, Baile dos Mateus e produção cordelística de Manoel Limão), às discussões de gênero, sexualidade, patrimônio, memória, literatura de cordel dentro do contexto dos estudos culturais.
} 


\section{UN REGARD SUR L'ENSEIGNEMENT DE L'HISTOIRE DANS LES MUSÉES DES SCIENCES}

Resumé: Sur la base des définitions variées des musées et de leurs potentiels éducatifs, nous avons l'intention d'analyser cette étude, conformément à la Déclaration de Rio de Janeiro de 1958 et à d'autres décrets / lois, tels que la loi 11.904/2009 et les Lignes directrices nationales sur les programmes d'études - Base nationale Curriculum commun et la matrice d'examen national des lycées, en réfléchissant à la manière dont les musées scientifiques en tant que diffuseurs de la culture scientifique, leurs relations entre science, technologie, société et histoire, peuvent être explorés parmi leurs possibilités d'intégration avec l'enseignement de l'histoire.

Mots-clés: L'enseignement de l'histoire. Musées. Musées scientifiques. Éducation.

\section{UNA MIRADA A LA ENSEÑANZA DE LA HISTORIA EN LOS MUSEOS DE CIÊNCIAS}

Resumen: Con base en las variadas definiciones de los museos y sus potencialidades educativas, pretendemos analizar este estudio, en línea con la Declaración de Río de Janeiro de 1958 y otros decretos / leyes, como la Ley 11.904 / 2009 y los Lineamientos Curriculares Nacionales - Base nacional. Currículo Común y Matriz Nacional de Exámenes de Bachillerato, pensando cómo los museos de ciencia como divulgadores de la cultura científica, sus relaciones entre ciencia, tecnología, sociedad e historia, pueden explorarse entre sus posibilidades de integración con la Docencia de Historia.

Palabras-clave: Enseñanza de la historia. Museos. Museos de ciencias. Educación.

\section{Introdução}

No ano de 1958, no Rio de Janeiro foi realizado o Seminário Regional da UNESCO, o qual tratou sobre as funções educativas dos museus, de modo a evidenciar sua importância para a sociedade. E, para isso, foram discutidos os elementos chaves que são pertinentes à temática, tais como a definição de museu, ações museológicas, exposições e outros. E oferecendo como resultado das discussões, foi produzida uma Declaração, a qual tomaremos por base para o presente trabalho, bem como outros documentos, como, por exemplo, a BNCC, a Matriz do ENEM e os Parâmetros Curriculares do Estado de Pernambuco. A Lei 11.904/2009 define o museu como:

Um estabelecimento permanente, administrado para satisfazer o interesse geral de conservar, estudar, evidenciar através de diversos meios e essencialmente expor, para o deleite e educação do público, um conjunto de elementos de valor cultural: coleções de interesse artístico, histórico, científico e técnico, jardins botânicos, zoológicos e aquários, etc. (LEGISLAÇÃO SOBRE MUSEUS, 2012, p. 89)

Atendendo a essas características, os museus de ciência desenvolvem suas atividades educativas de maneira a colaborar com o desenvolvimento social e científico, por meio de suas exposições, no qual são agregadas a um valor educativo que busca transpassar suas peças/experimentos para chegar ao entendimento de fenômenos por 
parte do visitante. Uma vez que nesse tipo de museu, pode-se facilmente associar objetos originais, réplicas, maquetes, documentos e etc. Os quais serão justamente os recursos que possibilitarão a vivência científica com o aprendizado.

Como este trabalho se propõe a discutir as possibilidades de ensinar história em um museu de ciência, unindo os elementos científicos, tecnológicos, sociais, culturais, dentre outros:

Espera-se que esses processos considerem as capacidades dos sujeitos de: (I) compreender assuntos sociocientíficos, (II) formular visões próprias e pontos de vista sobre esses assuntos, (III) reconhecer as forças sociais, políticas e econômicas que influenciam as atividades científicas e tecnológicas, (IV) tomar decisões de forma responsável e informada (considerando componentes morais e éticos) e (v) atuar em sua realidade. (MARANDINO, 2016, p 15).

Entendemos que ensinar história nos museus de ciência pode ocorrer por meio de práticas que visam considerar o contexto sociocultural das práticas científicas em um ambiente de educação não formal como acontece nos centros e museus de ciências, por serem locais que proporcionam o diálogo entre a ciência e a sociedade com suas exposições e ações educativas.

Em seu artigo $1^{\circ}$ a - Lei de Diretrizes e Bases Lei 9.394/199 (LDB, 1996), já apresenta que a educação abrange vários processos formativos e, portanto pode ser desenvolvida em diversos ambientes, dentre eles, os museus de ciências, os quais são locais que valorizam a experiência de aprendizado extraescolar, capaz de vincular a educação escolar com outros aspectos da vida de seus visitantes, tais como as práticas sociais.

Nos artigos: I - linguagens e suas tecnologias; II - matemática e suas tecnologias; III - ciências da natureza e suas tecnologias; IV - ciências humanas e sociais aplicadas, (LDB, 1996) da LDB, na área das ciências humanas e sociais aplicadas, a terminação tecnologias não é adjetivada como corriqueira, principalmente se tratando da história que, por muitas vezes, não se faz uso da tecnologia como recurso didático para tornar seu campo mais prático. Com isso, vimos que os muitos museus de ciências existentes no mundo, trazem possibilidades de abordar a história de forma bem mais prática, dinâmicas e significativas em suas exposições. Como ocorre no Espaço Ciência (PE), no Museu do Amanhã (RJ), no Amercan Museum of Natural History (EUA) e outros.

Ensinar história em um museu, até mesmo o de ciência, se dá por uma perspectiva de abordar com um novo olhar para a maneira de como fazer o aprendizado acontecer, a partir da contextualização dos conteúdos, as visitas guiadas, e o uso de 
estratégias bem pensadas que se enquadrem no conteúdo que o professor pretende mostrar, ensinar e construir com seus alunos. Partindo desses pressupostos conseguimos observar a possibilidade de uso dos Museus de Ciência como espaço educativo, pelo fato de compreender o potencial educativo dos museus em proporcionar práticas educativas significativas (BITTENCOURT, 2011).

Uma vez que a partir das transformações sociais, políticas e econômicas ocorridas durante o século XX passaram a exigir mudanças nas ações das escolas e no processo de ensino de modo a estender para além de seus muros, as responsabilidades pela educação na qual outrora saíram dos ambientes familiares e chegaram às escolas, e que por sua vez se ampliaram a outros espaços, como os museus, na atualidade temos que elas participam de forma mais ativa para formação e construção da socialização dos sujeitos.

\section{Entendendo as Diretrizes Curriculares de História na segunda metade do século XX}

Em 1997, o Ministério da Educação e do Desporto (MEC) lança a proposta da formulação dos Parâmetros Curriculares Nacionais, que na fala inicial do documento, o então Ministro da Educação e do Desporto, Paulo Renato de Souza, traz como objetivo dos parâmetros para o Ensino Fundamental, como proposta a iniciativa de auxiliar o professor:

[...] na execução do seu trabalho, compartilhando seu esforço diário de fazer com que as crianças dominem os conhecimentos que necessitam para crescerem como cidadãos plenamente reconhecidos e conscientes de seu papel em nossa sociedade [...] o propósito do Ministério da Educação e do Desporto, ao consolidar os parâmetros, é apontar metas de qualidade que ajudem o aluno a enfrentar o mundo atual como cidadão participativo, reflexivo e autônomo, conhecedor de seus direitos e deveres. (PCN's, 1997)

O Ensino Fundamental ficou estruturado levando em consideração também a organização da estrutura dos Parâmetros Curriculares Nacionais para o Ensino os temas transversais para cada disciplina, como podemos verificar no organograma abaixo: 


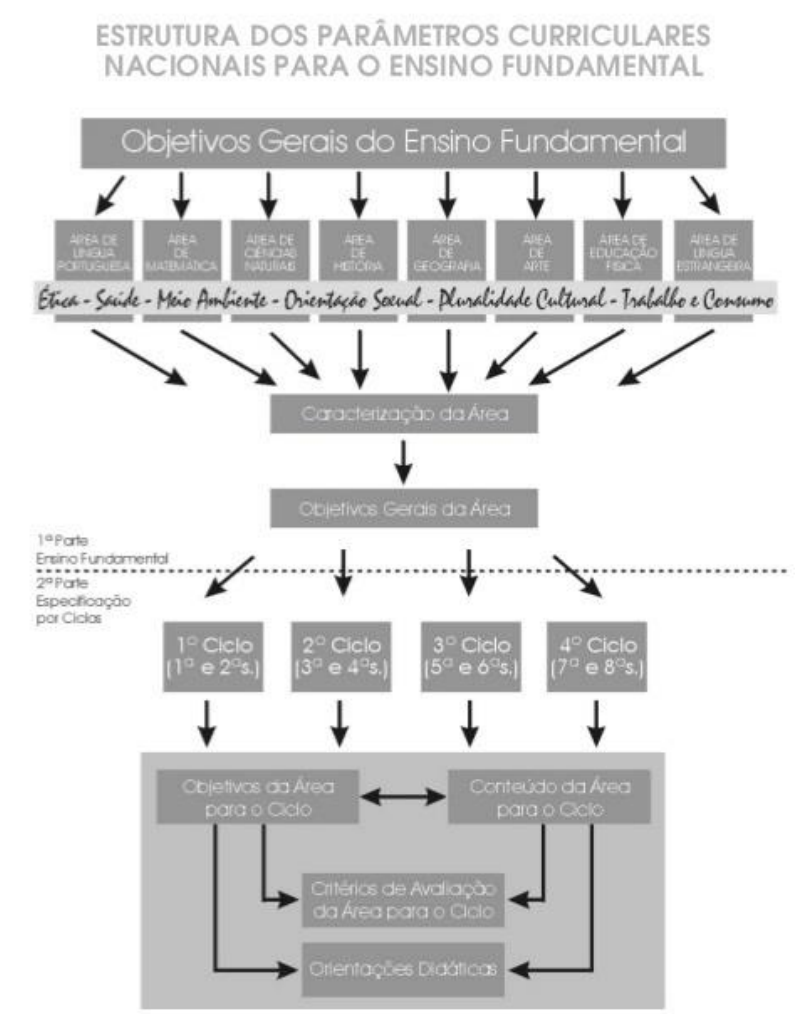

Estrutura Geral - Parâmetros Curriculares Nacionais. Arquivo: MEC.

Com base nessa proposta geral, o documento reuniu as disciplinas de História e Geografia, estruturando seus objetivos e finalidades para cada segmento da educação básica. Para a disciplina de História no Ensino Fundamental tinha-se como objetivo para a composição curricular da disciplina, que "ao longo do ensino fundamental os alunos gradativamente pudessem ler e compreender sua realidade posicionar-se fazer escolhas e agir criteriosamente" (PCN - História, 1997, p. 41).

Para que essas formas de leitura e compreensão dos conteúdos fossem realizadas, os PCN's tinham em sua divisão métodos de como trabalhar a aprendizagem da história em cada ciclo da educação. Para o $1^{\circ}$ Ciclo considerava-se:

[...] que as crianças estão no início da alfabetização, deve-se dar preferência aos trabalhos com fontes orais e iconográficas e, a partir delas, desenvolver trabalhos com a linguagem escrita. De modo geral, no trabalho com fontes documentais - fotografias, mapas, filmes, depoimentos, edificações, objetos de uso cotidiano -, é necessário desenvolver trabalhos específicos de levantamento e organização de informações, leitura e formas de registros. Espera-se que ao final do primeiro ciclo os alunos sejam capazes de: comparar acontecimentos no tempo, tendo como referência anterioridade, posterioridade e simultaneidade; reconhecer algumas semelhanças e diferenças sociais, econômicas e culturais, de dimensão cotidiana, existentes no seu grupo de convívio escolar e na sua localidade; 40 reconhecer algumas permanências e transformações sociais, econômicas e culturais nas vivências cotidianas das 
famílias, da escola e da coletividade, no tempo, no mesmo espaço de convivência; caracterizar o modo de vida de uma coletividade indígena, que vive ou viveu na região, distinguindo suas dimensões econômicas, sociais, culturais, artísticas e religiosas; identificar diferenças culturais entre o modo de vida de sua localidade e o da comunidade indígena estudada; estabelecer relações entre o presente e o passado; identificar alguns documentos históricos e fontes de informações discernindo algumas de suas funções." (PCN, 1997, p.39-40)

Para o $2^{\circ}$ Ciclo, o trato com os métodos requeria outras demandas, uma vez que os estudantes que estavam nessa fase de formação escolar além de serem alfabetizados, já tinham domínios de outras ordens da vida:

A particularidade do segundo ciclo reside no fato de os alunos dominarem melhor a linguagem escrita, possuírem experiências de trocas de informações e terem vivenciado momentos de questionamentos, comparações e trabalhos com ordenação temporal. Como no primeiro ciclo, os questionamentos são realizados a partir do entorno do aluno, com o objetivo levantar dados, coletar entrevistas, visitar locais públicos, incluindo os que mantêm acervos de informações, como bibliotecas e museus. Valorizando os procedimentos que tiveram início no primeiro ciclo, a preocupação de ensino e aprendizagem no segundo ciclo envolve um trabalho mais específico com leitura de obras com conteúdos históricos, como reportagem de jornais, mitos e lendas, textos de livros didáticos, documentários em vídeo, telejornais. (PCN, 1997, p. 45)

A leitura da história, e por que não dizer leitura de mundo, orientada através dos Parâmetros Curriculares Nacionais de História, nada mais era do que a proposta de realizar procedimentos didáticos que estimulassem nos estudantes o entendimento de processos históricos, a pluralidade cultural, as relações entre sujeitos sociais e os tempos da história.

Esses procedimentos serviriam para trabalhar os conteúdos, identificando suas relações com os patrimônios, mas, em nossa leitura, ao considerar essas questões o professor poderia desenvolver uma proposta pedagógica mais humanizada, na tentativa de considerar os repertórios de vida trazidos pelos estudantes.

Seguindo a linha de atender e conciliar a demanda da vida escolar e vida social, a BNCC trata:

Referência nacional para a formulação dos currículos dos sistemas e das redes escolares dos Estados, do Distrito Federal e dos Municípios e das propostas pedagógicas das instituições escolares, a BNCC integra a política nacional da Educação Básica e vai contribuir para o alinhamento de outras políticas e ações, em âmbito federal, estadual e municipal, referentes à formação de professores, à avaliação, à elaboração de conteúdos educacionais e aos critérios para a oferta de infraestrutura adequada para o pleno desenvolvimento da educação (BRASIL, S/D, p. 8). 
$\mathrm{Na}$ concepção de unificar as práticas educacionais, nas escolas de todo o país, a BNCC postula seus objetivos e conteúdos de forma generalizada para que as demais esferas governamentais adaptem os conteúdos à História local. Como identificamos nos Parâmetros Curriculares do Estado de Pernambuco:

HISTÓRIA - $6^{\circ}$ ANO - UNIDADES TEMÁTICAS: História: tempo, espaço e formas de registros; OBJETOS DE CONHECIMENTO: A questão do tempo, sincronias e diacronias: reflexões sobre o sentido das cronologias; (EF06HI01) Identificar diferentes formas de compreensão da noção de tempo e de periodização dos processos históricos (continuidades e rupturas) (BRASIL, S/D, p. 420-421).

$6^{\circ}$ ANO DO ENSINO FUNDAMENTAL - NÚCLEOS CONCEITUAIS E TEMÁTICOS: TEMPO; CONTEÚDOS: O ser humano como ser histórico em uma multiplicidade de tempos e espaços; Expectativas de Aprendizagem: EA2 - Identificar e comparar reguladores do tempo da sociedade em que os estudantes vivem e os reguladores de comunidades diferentes - de espaços do campo e da cidade e de culturas de outros tempos e espaços, evitando anacronismos e rompendo com a visão de tempo linear (PERNAMBUCO, S/D, p. 5).

$\mathrm{Na} \mathrm{BNCC}$ e nos Parâmetros do Estado de Pernambuco, para o $6^{\circ}$ ano do Ensino Fundamental, observamos a equivalência entre a estrutura dos conteúdos a serem ensinados e seus objetivos. No caso do estado, foram seguidas as recomendações para adaptações dos conteúdos que constam na BNCC fazendo correspondência com a História local.

\section{Museus de ciência como lugar de ensino}

No contexto dessas transformações, observamos os planos e programas legislativos e as diretrizes governamentais voltadas para o desenvolvimento de políticas e tecnologias educacionais que visam melhorias para a educação, como, por exemplo, o Ensino Remoto, o Ensino Híbrido e o acesso a ferramentas pedagógicas digitais a partir de aplicativos. Principalmente as transformações voltadas ao ensino de história que, com o passar do tempo, fora adquirindo cada vez mais o caráter social, como superação de um passado ainda presente de desvalorização da própria história como ciência detentora de conhecimentos gerais e superficiais.

Assim introduzindo um instrumento para auxiliar o ensino de história e outras fontes de saber histórico, como os museus. Na nossa proposta são os centros e museus de ciências que estimulam o conhecimento científico, bem como a experiência histórica e suas relações com as ações humanas e os fenômenos naturais. 
De acordo com a Lei $N^{\circ} 11.904$ de 2009, os museus são instituições que conservam, investigam, comunicam, interpretam e expõem objetos de seus acervos de acordo com suas tipologias, com a finalidade de estudo, pesquisa e educação. A ciência é segundo o manual de João Amado (2017), explicação, interpretação e sentido referenciado como esforço racional e metódico de compreensão da realidade, no qual é:

A explicação através do estabelecimento empiricamente comprovado de relação de causalidade, ou, a interpretação dos factos humanos tomando como base o sentido que e os sujeitos conferem às circunstâncias e aos atos que de algum modo vivenciam. (AMADO, 2011, p. 33)

Já a História, conseguimos traduzi-la como recurso que:

Fomenta a complementaridade das grandes orientações tradicionais do fazerciência: explicar [...] ou interpretar [...], assinala, ainda, o papel instrumental das teorias enquanto fontes (conceituais e metodológicas) de questionamento da realidade. É uma concepção adequada à compreensão científica dos fenômenos humanos caracterizáveis pela presença de determinismos externos e objetivos, e por toda uma esfera subjetiva onde impera o "sentido", a "interpretação" e a "decisão pessoal" que os sujeitos dão à vida e às circunstancias que a rodeiam. (AMADO, 2011, p. 33).

Devemos pensar a ciência como um conjunto de conhecimentos e investigações com suficiente grau de generalidade para resultar em convenções concordantes e relações objetivas baseadas em fatos comprováveis. (BITTENCOURT; BENCHETRIT; GRANATO, 2006, p. 11). E a distinção entre os conceitos de ciência e tecnologia podem ser entendidos no primeiro termo como aprender ou alcançar conhecimento; já o termo tecnologia como arte no sentido de habilidade ou ofício, o "como" (MASSABKI, 2011, p. 10):

A ciência e a tecnologia têm a função importante na vida social, principalmente na atualidade, tendo em vista a superação da ciência como fonte de verdade absoluta que busca humanizar-se na cultura e história, e encontrando nos museus lugar favorável ao desenvolvimento das relações entre ciência, tecnologia e sociedade. (MASSABKI, 2011, p. 11)

A formação do indivíduo, tanto nos seus aspectos básicos, quanto na sua formação científica, está cada vez menos restrita ao espaço escolar. Acompanhando essa realidade novos espaços foram criados a partir do surgimento de novas mídias que com o advento da internet, permitiram formas virtuais de divulgação e popularização da ciência para a sociedade.

Ganharam importância espaços complementares de formação do indivíduo, museus, centros de ciência, exposições, publicações, entre outros, pois 
contribuem efetivamente para a cultura científica, expandindo o conhecimento e sua importância no cotidiano da vida social moderna, na conservação do patrimônio histórico e cultural e para a construção da identidade cultural do povo:

Uma vez musealizado, o patrimônio cultural de ciência e tecnologia pode ser ao mesmo tempo, portador da memória dos "modos de conhecer" e, incentivador/divulgador das novas tecnologias e do próprio conhecimento científico [...] Os estudos com objetos de C\&T podem incluir muitas informações ligadas ao cotidiano da prática científica, informações essas que são fundamentais para o entendimento dos processos de trabalho e de produção. (ARAUJO; GRANATO, 2017, p. 2; 7)

Hartog (2006) nos leva a pensar que tipo de história pode ser ensinada em um museu de ciência, a partir das relações de como uma sociedade trata seu passado, e nos dá um apontamento significativo ao dizer que:

A noção devia poder fornecer um instrumento para comparar diferentes tipos de histórias, mas também e mesmo antes, eu acrescentaria agora, para iluminar modos de relação ao tempo: formas da experiência do tempo, aqui e lá, hoje e ontem. Maneiras de ser no tempo. (HARTOG, 2006, p. 263)

Tão logo, compreendemos esses instrumentos como os próprios experimentos encontrados nos museus de ciência, os quais nos indicarão de modo mais geral, qual viés da história podemos abordar e com isso também as possibilidades e influências temporais e espaciais que se refletem nas experiências históricas. De acordo Massabki (2011) e Curry (2000), uma característica muito presente nos museus de ciências é a interatividade dos visitantes com suas exposições, nessa perspectiva de experiência com o tempo e os fatos históricos, pode ser considerado como um grande laboratório de história, o qual nos permitirá não só experimentar, mas também materializar a história.

A interatividade encontrada nos museus e centros de ciências geralmente se apresentam sob as formas hands on (manual), minds on (mental) e heart on (emoção cultural):

A interatividade manual (hands-on) se dá pela manipulação direta do visitante; exposições que necessitam mecanismos acionados pelo visitante por um simples toque (push button); ou por meio da interatividade mental ("minds on"), que leva o visitante a uma compreensão científica: distinguindo o essencial do acessório, ver o que há de comum entre o que é aparentemente distinto, estabelecendo relações entre o que se vê no museu e no cotidiano; e ainda a interatividade cultural (heart on) explicando que, embora a ciência seja universal, a realidade na qual ela se desenvolve não o é. (CHELINI, LOPES, 2008, p. 232). 
Essa interatividade proposta pelos museus e centros de ciências devem levar em consideração os diversos aspectos de aprendizagem e contextos sociais, culturais, científicos que os visitantes/alunos podem trazer. Por isso, essa forma de abordagem faz com que a explicação se torna real, uma vez que nesses espaços podem ser tocadas e manipuladas. Essas ferramentas ajudam a contextualização, atraem o visitante e criam um ambiente muito mais atrativo.

Nesse contexto, o museu de ciência como propagador do patrimônio científico, exerce função de catalisador no processo de identificação dos sujeitos com a história, o qual além de traduzir os fenômenos, também os conservará e os aproximará do seu público de modo a trazer-lhes uma compreensão dos acontecimentos passados. E. assim como nas reformas dos templos no Japão, os contatos com os experimentos dos museus de ciência atualizam os fenômenos em escalas diversas.

Considerando que um objeto patrimonial não funciona sozinho, ele precisa estar inserido em um quadro de memória que lhe dê sentido, necessita de uma rede de significados que lhe potencialize um significado particular. Ao eleger determinados bens materiais ou imateriais como pertencentes ao patrimônio cultural da comunidade, automaticamente selecionamos os eventos com os quais desejamos compor a fala autorizada sobre o seu passado. Paul Ricouer (2007) nos faz atentar ao processo de seleção das memórias coletivas, alguns eventos são lembrados, ao passo que outros tantos são esquecidos ou mesmo ocultados (PACHECO, 2017).

Os objetos dos museus são possuidores de significados e, portanto tornam-se relevantes para compreensão dos fatos históricos proporcionando além de entendimento, o conhecimento e consciência de várias sociedades. Objetos de nosso cotidiano (mas fora desse contexto e, portanto capazes de atrair a observação) ou é estranhos à vida corrente (capazes, por isso, de incorporar à minha as experiências alheias) (MENESES, 1994, pg. 12).

Ou seja, nos acervos dos museus encontramos objetos que são detentores de significados e por isso contam a história sob diversas perspectivas, o que não ocorre nos supermercados e outros lugares que frequentamos em nosso dia-a-dia e não atentamos que podemos aprender algo.

Qualquer objeto pode funcionar como documento, mesmo que estes sejam criados para registrar informações. Nos museus, esses objetos também podem fornecer informações próprias não só do seu uso, mas também como documento. 
Por exemplo, se, ao invés de usar uma caneta para escrever, lhe são colocadas questões sobre o que seus atributos informam relativamente à sua matéria prima e respectivo processamento à tecnologia e condições sociais de fabricação, forma, função, significação etc. (MENESES, 1994, pg. 21).

Para tanto, essas classificações são definidas principalmente pelos historiadores, que geralmente atribui significado e contextualiza os objetos conforme suas descobertas.

Podemos elencar as reformas educacionais ocorridas principalmente durante $\mathrm{O}$ século XX se estendendo as realidades do século XXI como reflexo da escolarização como modo de melhorar e fortalecer a economia, aos modos do neoliberalismo, em conjunto com as políticas públicas que nortearam seus rumos, por meio dos diversos programas que atinjam todos os níveis de ensino, aliados à interdisciplinaridade e aos denominados temas transversais que vão para além da sala de aula, também como sugeridos pelo documento dos PCN's.

A exemplo disso observamos as intervenções dos museus de ciência que desenvolvem papel importantíssimo nesse processo educacional, o qual estabelece um discurso significativo entre o ensino (de história) e a prática.

Santos (2000) vai dizer que:

Ao comparar as sociedades às próprias imagens refletidas em espelhos por elas forjadas para reproduzir identidades, e assim estabelecer correspondências entre as hierarquias em práticas sociais. Uma vez que nesse contexto, as identidades são transformações e reflexos do que são as sociedades por meio dos espelhos da ciência, tecnologia, educação, informação, o direito, a tradição e outros [...]Hoje é possível ir muito além da mecânica quântica. Enquanto esta introduziu a consciência no ato do conhecimento, nós temos hoje de introduzir no próprio objeto do conhecimento, sabendo que, com isso, a distinção sujeito/objeto sofrerá uma transformação radical. (SANTOS, 1989, p. 61)

Por isso, podemos observar de forma prática, as possibilidades de abordar e ensinar história nos museus de ciência como uma alternativa para inserir e fazer com que o visitante se perceba como integrante de uma sociedade, seja ela em escala global ou local, visto que um discurso científico hegemônico tende a privilegiar a história na versão dos vencedores (AZEVEDO, 2004) e deixando às margens os demais indivíduos. Ou seja, os museus de ciência por estabelecerem um diálogo significativo com seus visitantes, se volta ao conhecimento escolar e científico de modo prático, experimental e os fazem participes do mesmo processo histórico. 
Ensinar história em um museu ou centro de ciências torna palpáveis os elementos históricos, auxiliados pelas representações que os experimentos encontrados nestas instituições, ocasionam na tomada de consciência e pertencimento:

Os museus são, frequentemente, lembrados como "locais", "espaços culturais", que cuidam da preservação da memória dos povos. Os museus constituem importantes espaços de aprendizagens, contribuindo significativamente para o conhecimento, o respeito e a valorização do patrimônio sócio-histórico e cultural dos povos. (FONSECA, 2003, p. 224)

Trazendo esse pensamento de modo geral e o transportando aos museus e centros de ciências, podemos considerar as evidências e os vestígios do passado carregados de historicidade e, por isso mesmo, são capazes de contribuir com o desenvolvimento do processo histórico, principalmente por causa da interatividade, do lúdico, do diálogo e outras atividades propostas aos visitantes, com intuito de formar a consciência histórica.

É importante levar em consideração as temáticas abordadas nas exposições dos museus e suas relações com os conteúdos estudados pelos alunos/visitantes. Uma vez que esses espaços e suas exposições ampliam os olhares dos visitantes os fazendo desenvolver diferentes visões e percepções de um mesmo fenômeno, os leva, em sua maioria a compreensão de diferentes aspectos.

Ao entendermos que o papel educativo dos museus de ciência consiste não em ensinar determinados conteúdos, mas em construir um diálogo entre conceitos científicos e as vivências do seu público, e com isso proporcionar a concepção de pertencimento a esses fenômenos e ao mundo da ciência e tecnologia a partir do uso de recursos como as narrativas, às histórias e emoções, ou um tipo de "Cidadania Científica" que para Yurij Castelfranchi é defendida como:

A cidadania hoje é uma cidadania científica, ou seja, mesmo as pessoas com um nível muito baixo do que se chamava de "alfabetismo científico", consciente ou inconscientemente, se apropriam, no seu dia a dia, de uma série de informações de cunho científico e tecnológico que circulam em seu meio. Não apenas em relação ao uso de celular e computador, mas também quando as pessoas vão ao supermercado. Cada vez mais, elas começam a ler os rótulos do que compram... As pessoas circulam em um meio que é atravessado o tempo todo pela produção, apropriação e avaliação do conhecimento, o que as torna cidadão científicos e tecnológicos. (CASTELFRANCHI, 2016, p. 40)

Para reforçar essa ideia de cidadania científica, é perceptível em Pedretti e Albe (2016) a interface existente entre ciência e sociedade. Tais assuntos são propícios a 
desenvolver um tipo de cidadania que prioriza a compreensão e participação em discussão na área, de modo a causar um "empoderamento" nos indivíduos.

Ao conseguirem se relacionar e observar como refletem os princípios científicos, morais e outros, também o mundo físico e social, em suas próprias vidas. Construindo a cidadania científica por meio de uma alfabetização científica: "alfabetização científica implica nas capacidades de: analisar, sintetizar e avaliar informação; engajar em processos informados de tomada de decisão; direcionar perspectivas relacionadas à natureza da ciência, combinando ciência, ética e raciocínio moral" (PEDRETTI e ALBE, 2016, p. 11).

Esse processo de alfabetização científica é uma realidade mundial e proporciona a cidadania científica, uma vez que oferta recursos aos indivíduos para tomarem conhecimento de fatos e acontecimentos dos quais lhes mostrarão um horizonte de descobertas que, em sua maioria, já fazem parte da realidade que esses indivíduos estão inseridos e não se dão conta de suas relações, ou das relações existentes do macro para o micro, ou vice-versa, na esperança de alcançarem mudanças sociais mais significativas. Tendo em mente que o debate em educação científica deve se estabelecer não por meio de conteúdos e disciplinas científicas, mas sim de projetos sociais, daí as autoras defenderem uma educação sociocientífica.

Para tanto, e como justificativa legal ao uso dos museus de ciência como espaço educativo, encontramos nos textos dos PCN's as diretrizes e discussões de temas que abrangem à disciplina de história e outras ciências humanas, por meio de conhecimentos considerados importantes para vida escolar e social dos alunos. Justificando-se a partir dos processos históricos ocorridos no Brasil desde sua colonização até o tempo presente, bem como as influências oriundas de fatos mundiais. Os quais visando atender as novas demandas sociais e científicas se adaptavam e se reformularam possibilitando assim a interdisciplinaridade entre as ciências:

O momento, hoje, porém, é o de se estruturar um currículo em que o estudo das ciências e o das humanidades seja complementar e não excludentes. Busca-se, com isso, uma síntese entre humanismo, ciência e tecnologia, que implique a superação do paradigma positivista, referindo-se à ciência, à cultura e à história. Destituído de neutralidade diante da cultura, o discurso científico revela-se enquanto representação sobre o real, sem se confundir com ele. (PCN'S DE HISTÓRIA - ENSINO MÉDIO, 2002, p. 7).

Tais medidas se fazem necessárias e demasiada importante, uma vez que nesse processo histórico, a educação escolar brasileira fora muito prejudicada. Para 
acompanhar o ritmo de desenvolvimento não só histórico, mas também científico, observamos a ação dos PCN's, que em seus textos atentam para importância de reconhecer e identificar o sentido do ensino da História, apoiado em seus objetivos, para melhor consolidação de suas influências e resultados como ciência.

Já em um contexto diferenciado do texto da LDB, no que diz respeito a esse reconhecimento da História como ciência, onde:

A presença das tecnologias na área de Ciências Humanas dá-se a partir do alargamento do entendimento da própria tecnologia, tanto como produto quanto como processo. Se, enquanto produto, as tecnologias apontam mais diretamente as Ciências da Natureza e a Matemática, enquanto processo, remetem ao uso e às reflexões que sobre elas fazem as três áreas de conhecimento. (PCN'S ENSINO MÉDIO, 2002, p. 9).

Também podemos ter uma compreensão da tecnologia como fenômeno social, da qual nos possibilita observar o desenvolvimento de processos tecnológicos diversos, amparados nos conhecimentos das Ciências Humanas que, por sua vez, faz distinção das tecnologias das Ciências Humanas em sua especificidade ante as das Ciências da Natureza.

Produzindo nas Ciências da Natureza tecnologias "duras", ou seja, palpáveis configuradas em ferramentas e instrumentos materiais; Já as Ciências Humanas, por sua vez produzem o que é chamado de tecnologias ideais, isto é, ligadas ao pensamento e às ideias, e ainda ao uso que as Ciências Humanas fazem das tecnologias originárias de outros campos de conhecimento, como exemplo, o recurso aos satélites e à fotografia aérea na cartografia, dentre outros (PCN, 2002).

Partindo desses pressupostos, não nos restam dúvidas que tanto se faz possível, quanto se experimenta na realidade concreta o atributo de sentido no uso das tecnologias na área das Ciências Humanas, perpassando o campo da abstração e encontrando-se na contextualização dos conhecimentos da área de História.

E a partir de toda discussão em relação ao museu de ciência, ao ensino de História e as políticas que norteiam e validam suas práticas e teorias, verifica-se a necessidade de entender a ciência como ato cultural, que está atrelada a sua valorização como parte de uma produção humana necessitada não só de reconhecimento, mas, também, de incentivo desse patrimônio científico brasileiro, por meio de políticas públicas que visem e garantam essas ações.

Mas, falar disso, nos faz retomar a proposta da cidadania científica, ou ainda da alfabetização científica que proporciona um maior desenvolvimento social a partir do 
acesso a ciência, sua compreensão e aplicabilidade prática e cotidiana na vida dos indivíduos. E, por isso mesmo, que os museus, independentemente de suas tipologias, podem ser utilizados pelo professor de história com o mesmo sentido dado por Pacheco e Meneses: "educar para a percepção da aventura humana no tempo por meio do contato com o objeto" (PACHECO, 2009, p. 120), ou seja, buscar tornar a história desse objetivo algo palpável e que possa se entrelaçar as aprendizagens humanísticas e curriculares de história.

Contudo, isso depende de um planejamento prévio que possibilite a efetivação do aprendizado advindo com a visitação aos referidos espaços. Tal interação pode ser compreendida como uma via de mão dupla, ao possibilitar trazer o museu para a sala de aula, e ainda a sala com seus conteúdos para os museus (PACHECO, 2012, p. 73).

As propostas das exposições dos museus de ciência se baseiam em processos e práticas de caráter objetivo e/ou subjetivo, mediante experimentos que proporcionem aos indivíduos se transformarem e compreenderem as realidades históricas de seu entorno. Caracterizando essa prática como de natureza moral, que consiste no aperfeiçoamento moral do humano, ou seja, o ensino de história no museu de ciência norteia os indivíduos a buscarem suas liberdades, no sentido de perceber-se e reconhecer-se como ser social e agente transformador da própria vida e consequentemente, da história inseridos nos fenômenos naturais, num contexto relacionado às questões sociais e culturais.

Diante disso compreendemos os que museus têm potencial para transformar e refletir o desenvolvimento da sociedade sob vários aspectos, dentre os mais comuns os sociais, culturais, econômicos políticos e assim por diante. No caso do museu de ciência, observamos um entrelaçamento entre arte, ciência e história capazes de transpor barreiras reais e imaginárias, quanto ao que se refere às limitações cognitivas.

\section{Conclusão}

Neste artigo buscamos tratar por meio da Legislação e Declaração do Rio de Janeiro (1958), relacionar os discursos desses documentos para compreender a importância de suas ações para a comunidade científica - acadêmica e escolar - os quais desenvolvem papel importante perante a sociedade. Tendo nos museus de ciências a possibilidade de um laboratório de História, o qual nos permitirá não só experimentar, mas também materializar a História da Ciência. 
DOI: 10.47694/issn.2674-7758.v2.i6.2020.149166

Sendo o museu essa instituição que conserva, prioriza aquilo que passou por uma escolha, compreendemos a sua relevância e representação social dentro de um contexto histórico, bem como esse lugar museu dentro do diálogo de produções didáticas para o ensino de história.

Deste modo, não podemos perder de vista a atratividade do museu por ser museu, ter sua funcionalidade enquanto museu, fomentando saberes que auxiliam no sentido aos conhecimentos escolares.

O museu de ciência, neste sentido, como recurso para ensinar história, se faz ferramenta pedagógica importante, devido a sua dinâmica de conteúdos, que versam muito próximas aos que as Diretrizes Curriculares Nacionais propõem na composição do currículo escolar de história.

Assim, podemos dizer que os museus de ciência contribuem para construção de um saber interdisciplinar, e na perspectiva do ensino de história, tais recintos ofertam uma compreensão de saberes teóricos e práticos, favorecendo transformações e melhorias para os indivíduos e a para sociedade.

\section{Referências}

ABUD, Kátia Maria. Ensino de História. São Paulo, Cengagem: Learning, 2010, Coleção ideias em ação. Cap. 8 Espaço da História: Ensino e Museus.

ÁLVAREZ Valente, MARIA Esther; ROSEMBERG Handfas, Ethel. O patrimônio cultural científico e tecnológico brasileiro e a importância de políticas públicas para sua preservação. Revista Ciências Estratégicas, v. 20, n. 28, julio-diciembre, 2012, p. 271284.

AMADO, João. (org.) Manual de investigação qualitativa em educação. 3. ed. Coimbra: Imprensa da Universidade de Coimbra, 2017.

AZEVEDO, Janete M. Lins de. A educação como política pública. 3. ed. Campinas/SP: Autores Associados, 2004.

BRASIL. Base Nacional Comum Curricular. Brasília: MEC, 2017. Disponível em: http://basenacionalcomum.mec.gov.br/images/BNC C_20dez_site.pdf. Acesso em: 13 set. 2020.

Lei $N^{o}$ 11. 904/2009. Disponível em: <http://www.planalto.gov.br/ccivil_03>. Brasília DF. 14 de Jan. de 2009. Acesso em 26-12-2017.

- Ministério da Educação. Secretaria da Educação Média e Tecnológica. Parâmetros Curriculares Nacionais $+(P C N+)-$ Parte IV - Ciências Humanas e suas Tecnologias. Brasília: MEC, 2002. 
BRASIL. Diretrizes Curriculares Nacionais Gerais da Educação Básica / Ministério da Educação. Secretaria de Educação Básica. Diretoria de Currículos e Educação Integral. Brasília: MEC, SEB, DICEI, 2013.

. MINISTÉRIO DA EDUCAÇÃO E DO DESPORTO. Parâmetros Curriculares Nacionais para o Ensino Fundamental. Brasília: MEC - Secretaria de Educação Fundamental (SEF), 1997.

CERTEAU, Michel de. A invenção do cotidiano. Artes de fazer. 2 ed. Trad. Ephraim Ferreira Alves. Petrópolis: Vozes, 1996.

CHARTIER, Roger. A história cultural: entre práticas e representações. 2. ed. São Paulo: DIFEL, 2002.

CHELINI, Maria-Júlia Estefânia; LOPES, Sônia Godoy Bueno de Carvalho. Exposições em museus de ciências: reflexões e critérios para análise. Anais do Museu Paulista. v. 16. n. 2. jul.-dez. 2008.

CURY, Marília Xavier, Estudos sobre centros e museus de ciências: subsídios para uma política de apoio, São Paulo. 2000.

FONSECA, Selva Guimarães. Didática e Prática de Ensino de História: experiências, reflexões e aprendizados. Campinas: Papirus, 2003.

GUIMARÃES, Emanuel. 2013. O Museu como Fator de Desenvolvimento Regional: O Impacto Econômico do Museu. Ensaios e Práticas em Museologia. Porto, Universidade do Porto, Faculdade de Letras, DCTP, v. 3, 2013, p. 40-53.

HARTOG, François. Tempo e patrimônio. Varia História, 22. (2006).

MARANDINO, M. A pesquisa educacional e a produção de saberes nos museus de ciência. Hist. ciências-saúde-Manguinhos, Rio de Janeiro, v. 12, supl. p. 161-181, 2005.

educadores. et al. São Paulo: FEUSP, 2016.

M. Controvérsias em Museus de Ciências: reflexões e propostas para

MASSABKI, Paulo H. B. Centros e museus de ciência e tecnologia. 2011. 274f. Dissertação (Mestrado) - Faculdade de Arquitetura e Urbanismo, Universidade de São Paulo, São Paulo, 2011.

MASSARANI, Luisa; MERZAGORA, Matteo; RODARI, Paola (orgs.). Diálogos \& ciência: mediação em museus e centros de Ciência. Rio de Janeiro: Museu da Vida/Casa de Oswaldo Cruz/Fiocruz, 2007.

Luisa; NEVES, Rosicler; AMORIM, Luís (orgs.). Divulgação científica e museus de ciências: O olhar do visitante - Memórias do evento. Rio de Janeiro: Museu da Vida/Casa de Oswaldo Cruz/Fiocruz, 2016.

MCMANUS, Paulette. Educação em museus: pesquisas e prática / Paulette McManus; organizadoras Martha Marandino e Luciana Monaco. São Paulo: FEUSP, 2013. p. 97. 
MENESES, Ulpiano T. Bezerra. Do teatro da memória ao laboratório da História: A exposição museológica e o conhecimento histórico. Anais do Museu Paulista. São Paulo. n. ser. v. 2 p. 9-42 jan./dez. 1994.

PACHECO, Ricardo de Aguiar. Ensino Escolar de História como Alfabetização Humanística. Ágora, Santa Cruz do Sul, v. 15, n. 2, p. 116 a 123, jul./dez. 2009. Disponível em: http://online.unisc.br/seer/index.php/agora/article/viewFile/1850/1356. Acesso em: 11/11/2017.

. O patrimônio histórico: objeto de pesquisa do historiador. História Unicap, v. 4, nº.7, Jan./Jun. 2017.

. O museu na sala de aula: propostas para o planejamento de visitas aos museus. Revista Tempo e Argumento, Florianópolis, v. 4, n. 2, p. 63- 81, jul-dez. 2012.

SANTOS, Boaventura. Introdução à ciência Pós-Moderna. Rio de Janeiro: Graal, 1989. 